\title{
Flowering and Fruiting Phenology of Some Forest Plant Species in the Remnants of Combretum - Terminalia Woodlands of Western Ethiopia
}

\section{Dereje Mosissa*}

Ethiopian Biodiversity Institute, Assosa Biodiversity Center, Forest and Range Land Biodiversity Case Team, Ethiopia

*Corresponding Author: Dereje Mosissa, Ethiopian Biodiversity Institute Assosa Biodiversity Center, Forest and Range Land Biodiversity Case Team, Ethiopia.

Received: September 06, 2019; Published: October 28, 2019

DOI: 10.31080/ASAG.2019.03.0697

\begin{abstract}
Phenological background information for Combretum-Terminalia wood land species is limited in particular from lower altitudes. Flowering and fruiting phenology was monitored for 24 plant species ranging between 610-1580 m.a.s.l. of the Benishangul Gumuz Regional State North West Ethiopia. The dates of first flowering, peak flowering, end of flowering, first fruiting, peak fruiting and flowering period were recorded. There was a wide variation in onset of flowering, long flowering duration, a relative synchrony between the onset of flowering and fruiting. These results suggest that the species have evolved various phenological strategies as adaptations to the short growing season with limited resources and pollinators in this harsh environment at extremely lower elevations. With a background of climate change, local plant species will represent an advancing trend in onset of flowering and fruiting.

Keywords: Adaptation; Combretum-Terminalia; Climate Change; Phenology; Pollinators
\end{abstract}

\section{Introduction}

Studies of tropical rain forests suggest that phenological patterns of trees are driven by a variety of factors including: abiotic characters such as rainfall, irradiance, and temperature; mode of seed dispersal; activity of pollinators or seed dispersers; variation in germination conditions; canopy position and relative abundance of the trees themselves [50]. The timing of various phenological activities such as germination, bud break, flowering, fruit dehiscence, and leaf drop is important for survival and reproductive success of many plant species. Abiotic environmental conditions such as rain change in temperature, presence/absence of pollinators, competitors, and herbivores have been shown to play a significant role in timing of various phonological events [1-6]. Natural selection has also been considered to play some role in determining the phenological patterns of plant species [7]. Phenological studies are also important in understanding species interrelations and their interaction with the environment. Variations in phenophases among individuals of the same species or different species have been linked to environmental perturbations [8].

An understanding of the phenological patterns in different geographical regions and of factors underlying these patterns is important for a number of reasons. First, frugivores are the dominant group of vertebrates in most tropical forests and regional differences in their abundance may be caused by differences in food availability. Second, an understanding of phenological patterns and factors underlying these patterns will assist conservation scientists in predicting consequences of perturbations such as atypi- cal climatic events or global warming. Third, phenological patterns are linked to many processes governing forest function and structure including: population biology of pollinators, dispersers, seed predators, and herbivores, interspecific competition among trees, and processes of primary production. Thus, an understanding of what governs phenological process is valuable in understanding forest function and structure and in providing the basis for developing management options [51].

Considerable amount of phenological data is available on different plant species from different parts of the world including tropical savanna and semi-deciduous forest of Venezuelan Ilanos (South America) [9], dry tropical forest in Ghana [10], NE Spain [11-13], Panama [14], Mexico [15], tropical rain forest in Malaya [16], semiarid grassland in the Rock mountain, USA [17], and tibetan plateau [18].

A number of studies on phenology of different plant species from different parts of the world have also been undertaken which include those from a subtropical humid forest in North-Eastern India [19,20], Kumaun Himalayan forests [21, 22], deciduous forest of Bandipur in peninsular India [23], Shervaroys, Southern India [24], tropical moist forest of Western Ghats in Karnataka [25],Hathinala Forest in Uttar Pradesh [26], alpine expanse of North-West Himalaya [27], Orissa coast [28], tropical montane forests in the Nilgiris [8], Kolhapur region (Maharashtra) [29], and Katerniaghat wildlife sanctuary situated in the Himalayan Terai region in Uttar Pradesh [30], Northeastern India [31]. However, studies on phenology of 
broad and deciduous leaf plants of Combretum-Terminalia woodland was minimal. Therefore, the present paper deals with phenological observations of twenty four leguminous plants growing at eight different sites in Benishangul Gumuz Regional State over a period of two years from 2017 till 2018/19 as these sites represent most of the plant diversity of this region.

\section{Materials and Methods}

Site description

The assessment area that is the Northwestern Ethiopia specially of Benishangul-Gumuz Region, which is situated within $11^{\circ} 00^{\prime}$ 0.00 " N Latitude and $35^{\circ} 44^{\prime} 59.99^{\prime \prime}$ E Longitude (Figure 1). The region is well described by Combretum-Terminalia vegetation which is also center of endemism to some important trees and lilies. Combretum-Terminalia woodland or wooded grassland is a vegetation type with an open over storey that is dominated by Combretum molle $(10-13 \mathrm{~m})$ and Terminalia mollis $(15-17 \mathrm{~m})$. This vegetation type is a fire climax community that has replaced dry evergreen forest on ridges and upper slopes in the western and northwestern part of Ethiopia [48]. Combretum molle woodland is probably a fire induced vegetation type that has replaced evergreen bush land (Be) or scrub forest on wetter upland areas. "Ethiopian undifferentiated woodland" is virtually equivalent to Combretum-Terminalia woodland and wooded grassland described in the atlas of potential natural vegetation types of Ethiopia $[48,49]$.

Different sampling sites, that is, Mandura, Dangur, Guba, Sherkole, Homosha, Kurmuk, Assosa and Bambasi woredas' were selected for data collection. These sites were chosen as they represent most of the plant diversity of Benishangul Gumuz Regional State (BGRS). Figure 1 shows the location of eight sites on the map of BGRS.

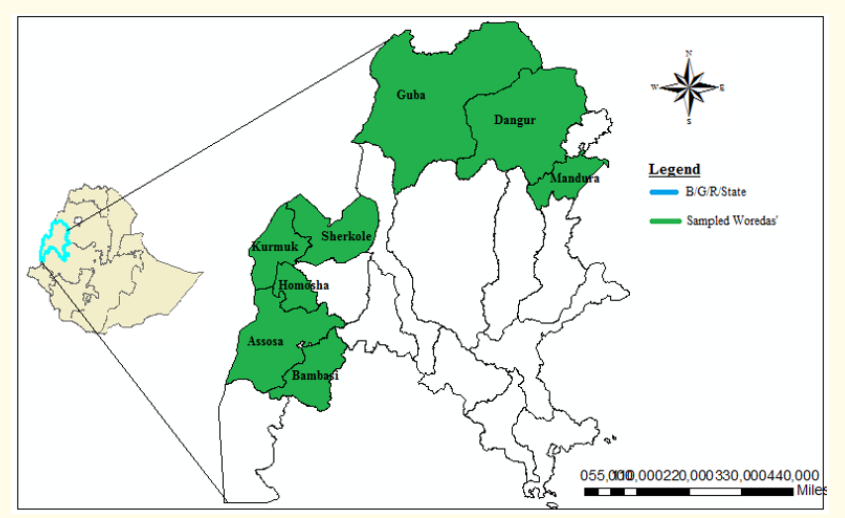

Figure 1: Map of the assessment area.

\section{Climate}

The area is known in its uni-modal rain fall pattern with a long rainy season from May to October. The period from November to April is relatively dry. The mean annual temperature is $24^{\circ} \mathrm{C}$ (Figure 2, Figure 3 ). The soils are young and of volcanic origin, characterized by sandy or sandy loam, and it is shallow at steep convex slopes and at lower altitudes [47].

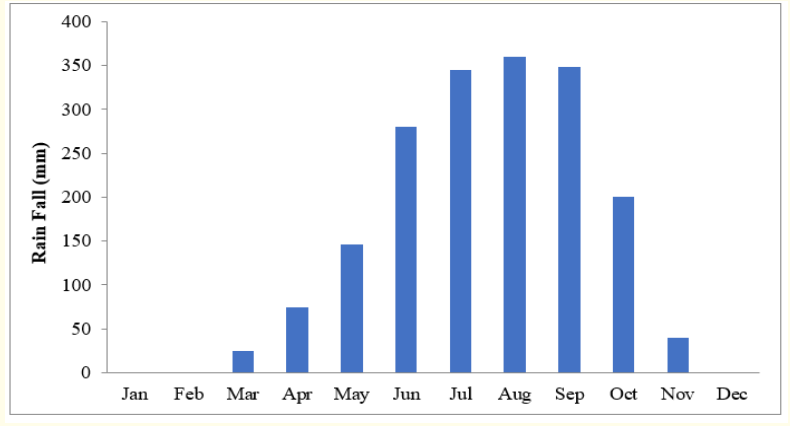

Figure 2: Mean monthly rainfall in mm for Benishangul Gumuz Regional State.

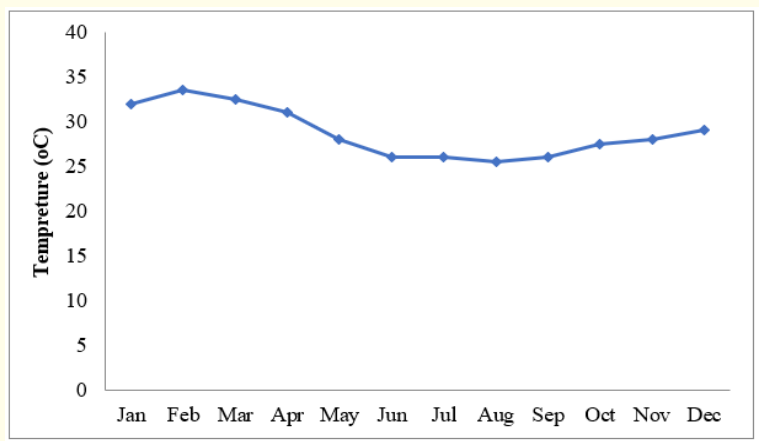

Figure 3: Mean maximum and minimum temperatures in ${ }^{\circ} \mathrm{C}$ for Benishangul Gumuz Regional State.

\section{Phenological data}

The data for each species was collected from a minimum of two sampling sites. At each site, one mature and healthy plant from the population of that species was fixed as reference for the study. The observations were made on the marked plant and 10-15 of its closest neighbours (minimum 6 plants if more plants were not available for a particular plant species at a particular site) for a period of 2 years starting from September 2017 up to December, 2018/19.

The areas with the plants under study were visited quarterly to record presence/absence of different phenological events or phenophases: flowering (FL), and fruit setting (FR). The information for the initial date and the last date when these various phenophases were observed was recorded.

A phenophase was considered to be active in the population just when it was observed in at least $5 \%$ of the crown in a minimum of $20 \%$ of the studied plants [12]. Phenophase calendars for each species were prepared and were studied for the interpretation of the overall results.

\section{Results}

A total of 24 plant species classified under 11 families were identified and documented in the study area. Families Fabaceae and Combretacea ranked first and second with their total species number 13 and 2 in the same order (Table 1, Figure 4). 


\begin{tabular}{|c|c|c|c|c|c|c|c|c|c|c|c|c|c|}
\hline \multirow[t]{2}{*}{ Name of Plant } & \multirow[t]{2}{*}{ Phenophase } & \multicolumn{12}{|c|}{ Months } \\
\hline & & Sept & Oct & Nov & Dec & Jan & Fab & Mar & Apr & May & Jun & Jul & Aug \\
\hline \multirow{2}{*}{ Acacia polyacantha } & Flowering & & & & & & & & & & & & \\
\hline & Fruiting & & & & & & & & & & & & \\
\hline \multirow{2}{*}{ Acacia senegal } & Flowering & & & & & & & & & & & & \\
\hline & Fruiting & & & & & & & & & & & & \\
\hline \multirow{2}{*}{ Acacia seyal } & Flowering & & & & & & & & & & & & \\
\hline & Fruiting & & & & & & & & & & & & \\
\hline \multirow{2}{*}{ Annona senegalensis } & Flowering & & & & & & & & & & & & \\
\hline & Fruiting & & & & & & & & & & & & \\
\hline \multirow{2}{*}{ Anogeissus leiocarpa } & Flowering & & & & & & & & & & & & \\
\hline & Fruiting & & & & & & & & & & & & \\
\hline \multirow{2}{*}{ Balanitesaegyptiaca } & Flowering & & & & & & & & & & & & \\
\hline & Fruiting & & & & & & & & & & & & \\
\hline \multirow{2}{*}{ Boswelliapapyrifera } & Flowering & & & & & & & & & & & & \\
\hline & Fruiting & & & & & & & & & & & & \\
\hline \multirow{2}{*}{ Cassia arereh } & Flowering & & & & & & & & & & & & \\
\hline & Fruiting & & & & & & & & & & & & \\
\hline \multirow{2}{*}{ Cordia africana } & Flowering & & & & & & & & & & & & \\
\hline & Fruiting & & & & & & & & & & & & \\
\hline \multirow{2}{*}{ Dalbergia melanoxylon } & Flowering & & & & & & & & & & & & \\
\hline & Fruiting & & & & & & & & & & & & \\
\hline \multirow{2}{*}{ Dichrostachys cinerea } & Flowering & & & & & & & & & & & & \\
\hline & Fruiting & & & & & & & & & & & & \\
\hline \multirow{2}{*}{ Entadaafricana } & Flowering & & & & & & & & & & & & \\
\hline & Fruiting & & & & & & & & & & & & \\
\hline \multirow{2}{*}{ Erythrina abyssinica } & Flowering & & & & & & & & & & & & \\
\hline & Fruiting & & & & & & & & & & & & \\
\hline \multirow{2}{*}{ Gardenia ternifolia } & Flowering & & & & & & & & & & & & \\
\hline & Fruiting & & & & & & & & & & & & \\
\hline Securidaca & Flowering & & & & & & & & & & & & \\
\hline longepedanculata & Fruiting & & & & & & & & & & & & \\
\hline & Flowering & & & & & & & & & & & & \\
\hline Senna obtusifolia & Fruiting & & & & & & & & & & & & \\
\hline & Flowering & & & & & & & & & & & & \\
\hline Senna occidentalis & Fruiting & & & & & & & & & & & & \\
\hline & Flowering & & & & & & & & & & & & \\
\hline Sterculia africana & Fruiting & & & & & & & & & & & & \\
\hline & Flowering & & & & & & & & & & & & \\
\hline Strychnos іппосиа & Fruiting & & & & & & & & & & & & \\
\hline Tamarindes indica & Flowering & & & & & & & & & & & & \\
\hline Tamarindes indica & Fruiting & & & & & & & & & & & & \\
\hline Terminalia laxiflorr & Flowering & & & & & & & & & & & & \\
\hline Terminalıa Iaxifiora & Fruiting & & & & & & & & & & & & \\
\hline Vitex doniang & Flowering & & & & & & & & & & & & \\
\hline Vitex aoniana & Fruiting & & & & & & & & & & & & \\
\hline 7izinhus abyssinica & Flowering & & & & & & & & & & & & \\
\hline Ziziphus abyssinica & Fruiting & & & & & & & & & & & & \\
\hline 7 Timb & Flowering & & & & & & & & & & & & \\
\hline ZIziphus mucronata & Fruiting & & & & & & & & & & & & \\
\hline
\end{tabular}

Table 1. Phenological diagrams of twenty four plant species belonging to eleven families. The yellow and redish colored bars indicate the whole period of appearance of different phenophases including flowering and fruiting. 


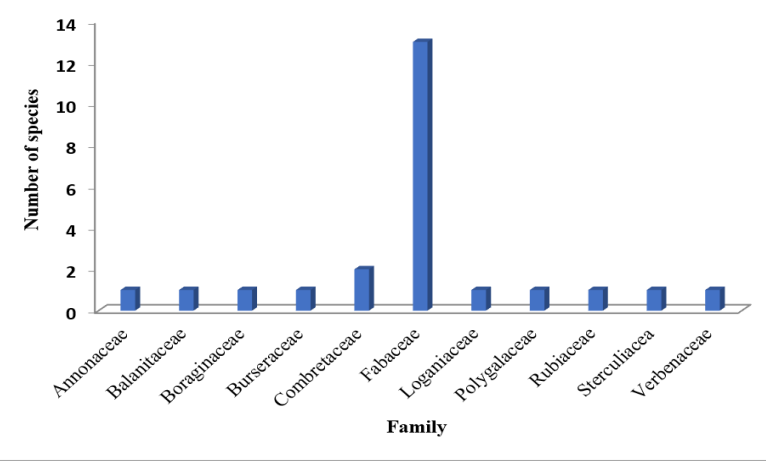

Figure 4: Taxonomy of sampled plant species.

This figure 4 reveals that percentage of plant species exhibiting each phenophase, that is, flowers, and fruits, showed almost a similar trend for years within each phenophase. Flower formation showed a peak in the beginning of summer $(60 \%)$ and another small peak during mid of winter and was almost evenly distributed through the rest of the year. Opposite trend was observed for fruiting which also showed a peak (66.67\%) at the end of summer and another small peak (53.33\%) during mid of summer period for all the years. Maximum percentage of plant species showing fruiting was observed in the months of October, December, and January (60\%) (Figure 5, Figure 6) which resulted in maximum seed set following these months. Comparison of results on observations of flowering in different plant species during the years recorded, reveals that maximum percentage of plant species (66.67\%) showing flowering was observed in the month of October, June and July during 2018/19.

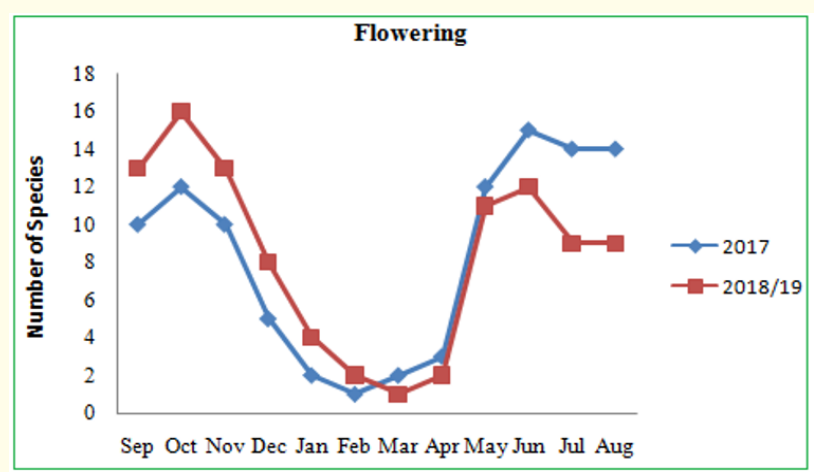

Figure 5: Percentage of plant species under study showing each phenophase: flowers during 2017 to 2018/19.

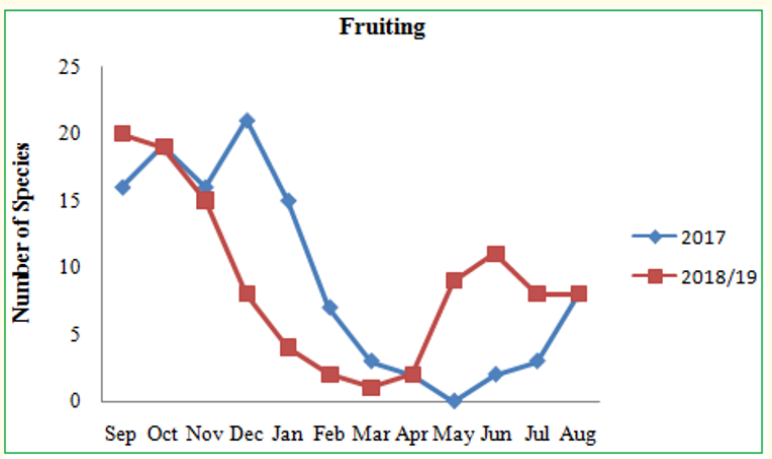

Figure 6: Percentage of plant species under study showing each phenophase: fruits during 2017 to 2018/19.
Figure 7 also shows phenological patterns of individual plant species studied. For each plant species, the whole period of appearance of different phenophases-like flowering, and fruiting, has been indicated for two consecutive years. The study reveals high phonological diversity for different phenophases studied among twenty four plant species. Moreover, for individuals of the same species, there was a significant difference in the appearance of different phenophases across different geographic ranges.

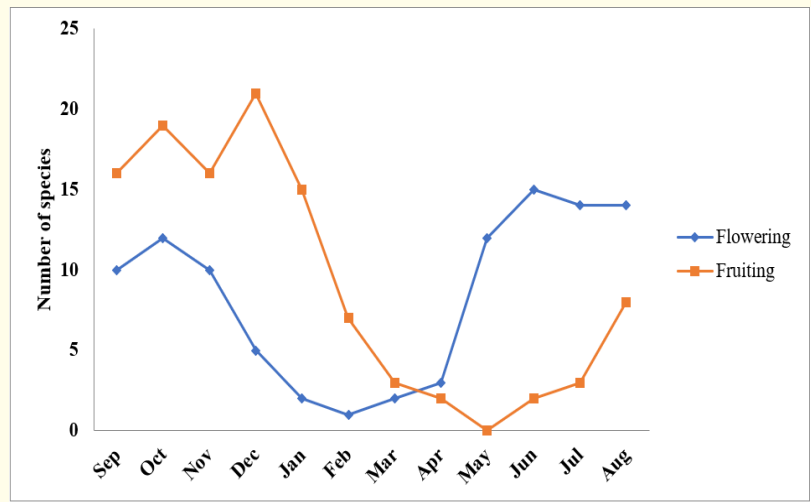

Figure 7: Percentage of plant species under study showing each phenophase.

\section{Discussion}

Our study reveals high phenological diversity for the two phenological patterns (flowers and fruits) among twenty four plant species growing in Western Ethiopia under similar environmental conditions for the two consecutive years, that is, 2017 and 2018/19. Changes in plant phenological patterns have been associated with the species specific plant structural architecture, availability and transfer of nutrients [33], plant growth rates [34], temperature [35], and water [36].

A comparison of observations on flowering time for the two years under study reveals an advancement of flowering time by about 2-4 weeks in the year 2018 for some species like Acacia senegal, Acacia seyal, Dalbergia melanoxylon, Entada africana., and Ziziphus mucronata as compared to that observed in 2017. This change in phenological shift can be attributed to increase in temperature in 2018 as compared to that reported for 2017. The total length of flowering period was extended by 2-4 weeks in 2018-19 as compared to 2017 for some species.

Some other studies have also demonstrated an association of advancement in flowering date with climate change. One study has reported an increase in the mean terrestrial surface temperature by more than $0.20 \mathrm{C}$ per decade ever since 1970 [37]. A number of other studies have shown an advancement of phenological events as a result of increase in temperature [38-41]. With the increase in the temperature, most of the species showed earlier flowering time period [39] and even increase in their time period of flowering (e.g., Bauhinia variegate Linn., Prosopis juliflora DC.). Similarly early flowering was observed for 24 out of the 32 plant species studied in semiarid grassland by Lesica and Kittelson [17]. 
The period of maximum activity of the flowering period (started at the beginning of summer and extended to the beginning of autumn) coincided with the observations of Pilar and Gabriel [12,32] Flower development dates have been shown to be synchronous among individuals of the same plant species studied which seems to be important in increasing the chances of outcross pollinations as suggested by Ollerton and Lack [42].

These changes in the phenological patterns can result in adverse effects on insect pollinators as well as herbivores (if the plant species is present in barren or wild areas) that depend on those species for food $[43,44]$. The changes in phenological patterns of plant's response to different temperature and rainfall availability have been shown to be species specific $[45,46]$. Hence changes in vegetation community species composition might also be responsible for changes in the phenology of the studied plants. The present study reveals that different plants of the same family (Leguminosae) flower at different times during the same year growing at same location under similar environmental conditions which can be attributed to species-specific plant structural architecture.

\section{Conclusion}

The present study reveals high phenological diversity for two different phenophases among twenty four plant species growing in western Ethiopia with tropical dry deciduous type of vegetation. This study would be of great help in knowing the timing of different phenophases of the studied plants which can be of interest to Ethiopian Biodiversity Institute and people of this region (or where similar climatic conditions prevail) who wish to plan for conservation of the species and wish to have flowers in their gardens round the year. So, they can select plants which flower during different parts of the year. This type of study can provide important insights into the biology of the plants concerned and reveal phenological pattern of surveyed species. This study would also be of great help for comparison over long duration of time. For example, to see if there is any change in the phenological patterns of the same plant species in next 10 or so years. Such comparative study could not be possible at this time since no relevant literature is available for this region.

\section{Bibliography}

1. E R Heithaus. "The role of plant-pollinator interactions in determining community structure". Annals of the Missouri Botanical Garden 61 (1974): 675-691.

2. G W Frankie. "Tropical forest phenology and pollinator plant coevolution". in Coevolution of Animals and Plants, L. E. Gilbert and P. H. Raven, Eds. (1975): 192-209.

3. H R Pulliam and M R Brand. "The production and utilization of seeds in plains grassland of south eastern Arizona". Ecology 56 (1975): 1158-1166.

4. P A Opler, et al. "Rainfall as a factor in the release, timing and synchronization of anthesis by tropical trees and shrubs". Journal of Biogeography 3 (1976): 231-236.
5. JN Thompson and M F Willson. "Evolution of temperature fruit/bird interactions: phenological strategies". Evolution 33 (1979): 973-982.

6. EW Stiles. "Patterns of fruit presentation and seed dispersal in bird disseminatedwoody plants in the eastern deciduous forest". The American Naturalist 116 (1980): 670-688, 1980.

7. G F Estabrook., et al. "When are two phenological patterns different?" Botanical Gazette 143.3 (1982): 374-378.

8. H S Suresh and R Sukumar. "Vegetative phenology of tropical montane forests in the Nilgiris, South India". Journal of the National Science Foundation of Sri Lanka 39.4 (2011): 333-343.

9. M Monasterio and G Sarmiento. "Phenological strategies of plant species in the tropical savanna and the semideciduous forest of the Venezuelan Ilanos". Journal of Biogeography 3 (1976): 352-356.

10. D Lieberman. "Seasonality and phenology in a dry tropical forest in Ghana”. Journal of Ecology 70.3 (1982): 791-806.

11. R Milla., et al. "Phenology of Mediterranean woody plants from NE Spain: synchrony, seasonality, and relationships among phenophases". Flora 205.3 (2010): 190-199.

12. CD Pilar and MM. Gabriel. "Phenological pattern of fifteen Mediterranean phanaerophytes fromQuercus ilex communities of NE-Spain". Plant Ecology 139.1 (1998): 103-112.

13. G Montserrat-Marti and C P'erez-Rontom'e. "Fruit growth dynamics and their effects on the phenological pattern of native Pistacia populations in NE Spain". Flora 197.3 (2002): 161174.

14. D De Steven., et al. "Vegetative and reproductive phonologies of a palm assemblage in Panama”. Biotropica 19 (1987): 342356.

15. S H Bullock and J A Solis-Magallanes. "Phenology of canopy trees of a tropical deciduous forest in Mexico". Biotropica 22 (1990): 22-35.

16. L Medway. "Phenology of a tropical rain forest in Malaya". Biological Journal of the Linnean Society 4.2 (1972): 117-146.

17. P Lesica and PM Kittelson. "Precipitation and temperature are associated with advanced flowering phenology in a semi-arid grassland". Journal of Arid Environments 74 (2010): 10131017.

18. M Shen., et al. “Influences of temperature and precipitation before the growing season on spring phenology in grasslands of the central and eastern Qinghai-Tibetan Plateau". Agricultural and Forest Meteorology 151.12 (2011): 1711-1722.

19. R P Shukla and P S Ramakrishnan. "Phenology of trees in a subtropical humid forest in north-eastern India”. Vegetation 49.2 (1982): 103-109. 
20. R P Shukla and P S Ramakrishnan. "Leaf dynamics of tropical trees related to successional status". New Phycologist 97.4 (1984): 697-706

21. PK. Ralhan., et al. "Phenological characteristics of the tree layer of Kumaun Himalayan forests". Vegetation 60.2 (1985): 91-101.

22. Y P S. Pangtey., et al. "Phenology of high-altitude plants of Kumaun in Central Himalaya, India". International Journal of Biometeorology 34.2 (1990): 122-127.

23. S N Prasad and M Hegde. "Phenology and seasonality in the tropical deciduous forest of Bandipur, South India". Proceedings: Plant Sciences 96.2 (1986): 121-133.

24. N Sivaraj and K V Krishnamurthy. "Flowering phenology in the vegetation of Shervaroys, South India". Vegetation 79.1-2 (1988): 85-88.

25. D M Bhat and K S Murali. "Phenology of understorey species of tropical moist forest of Western Ghats region of Uttara Kannada district in South India”. Current Science 81.7 (2001): 799805.

26. K P Singh and C P Kushwaha. "Diversity of flowering and fruiting phenology of trees in a tropical deciduous forest in India". Annals of Botany 97.2 (2006): 265-276.

27. R K Vashisthe., et al. "An exploration on the phenology of different growth forms of an alpine expanse of north-west Himalaya, India”. New York Science Journal 2 (2009): 29-42.

28. V P Upadhyay and P K Mishra. "Phenology of mangroves tree species on Orissa coast, India". Tropical Ecology 51.2 (2010): 289-295.

29. A R Kasarkar and D K Kulkarni. "Phenological studies of family zingiberaceae with special reference to Alpinia and Zingiber from Kolhapur region(MS) India". Bioscience Discovery 2 (2011): 322-327.

30. Bajpai., et al. "Phenological study of two dominant tree species in tropical moist deciduous forest from the Northern India". International Journal of Botany 8 (2012): 66-72.

31. A Lokho and Y Kumar. "Reproductive phenology and morphology analysis of Indian Dendrobium Sw. (Orchidaceae) from the northeast region". International Journal of Scientific and Research Publications 2 (2012): 1-14.

32. S H G Champion and S K Seth. "A Revised Survey of the Forest Types of India". The manager of Publications, Delhi, India (1968).

33. R E Sosebee and H H Wiebe. "Effect of phenological development on radiophosphorus translocation from leaves in crested wheatgrass". Oecologia 13.2 (1973): 103-112.

34. F G Taylor Jr. Phenodynamics of Production in a Mesic Deciduous Forest. US/IBP Eastern Deciduous Forest Biome, Oak Ridges National Laboratory, Oak Ridge, Tenn, USA (1972).
35. M Y Nuttonson. Wheat-Climate Relationships and the Use of Phenology in Ascertaining the Thermal and Photo-Thermal Requirements of Wheat; Based on Data of North America and Some Thermally Analogous Areas of North America, in the Soviet Union and in Finland, American Institute for Crop Ecology, Washington, DC, USA (1955).

36. J P Blaisdell. "Seasonal development and yield of native plants on the upper Snake River plains and their relation to certain climatic factors". US Department of Agriculture Technical Bulletin 1190 (1958): 1-68.

37. J Hansen., et al. "Global temperature change". Proceedings of the National Academy of Sciences of the United States of America 103.39 (2006): 14288-14293.

38. Y Julien and J A Sobrino. "Global land surface phenology trends from GIMMS database". International Journal of Remote Sensing 30.13 (2009): 3495-3513.

39. A Menzel., et al. "European phonological response to climate change matches the warming pattern". Global Change Biology 12.10 (2006): 1969-1976.

40. C Parmesan and G Yohe. "A globally coherent fingerprint of climate change impacts across natural systems". Nature 421.6918 (2003): 37-42.

41. S Piao., et al. "Variations in satellite-derived phenology in China's temperate vegetation". Global Change Biology 12.4 (2006): 672-685.

42. J Ollerton and A J Lack. "Flowering phenology: an example of relaxation of natural selection?" Trends in Ecology and Evolution 7.8 (1992): 274-276.

43. F Saavedra., et al. "Changes in flowering and abundance of Delphinium nuttallianum (Ranunculaceae) in response to a subalpine climate warming experiment". Global Change Biology 9.6 (2003): 885-894.

44. N C Stenseth and A Mysterud. "Climate, changing phenology, and other life history traits: nonlinearity and match-mismatch to the environment". Proceedings of the National Academy of Sciences of the United States of America 99.21 (2002): 1337913381.

45. I Ibanez., et al. "Forecasting phenology under global warming". Philosophical Transactions of the Royal Society B 365.1555 (2010): 3247-3260.

46. C Parmesan. "Influences of species, latitudes and methodologies on estimates of phenological response to global warming". Global Change Biology 13.9 (2007): 1860-1872.

47. Tesfaye Awas. "Plant Diversity in western Ethiopia: Ecology, ethnobotany and conservation". University of Oslo, Oslo (2007). 
48. White F. "The Vegetation of Africa: A descriptive memoir to accompany the UNESCO/ AETFAT/UNSO vegetation map of Africa".

49. Friis I., et al. "Diversity and endemism of the western Ethiopian escarpment- a preliminary comparison with other areas of the Horn of Africa". Biol. Skr. 55 (2010): 315-330.

50. VAN SCHAIK CP. "Phenological changes in a Sumatran rain forest". Journal of Tropical Ecology 2 (1986): 327-347.

51. EMMONS LH., et al. "Community structure of the frugivorefolivore forest mammals of Gabon". Journal of Zoology 199 (1983): 209-222.

Volume 3 Issue 11 November 2019

(C) All rights are reserved by Dereje Mosissa. 